\title{
A study on constraints in adoption of scientific aquaculture practices
}

\author{
M anoj K umar*, S. N. Ojha, Arpita Sharma and Raushan K umar \\ Fisheries Economics, Extension and Statistics (FEES) Division, Central Institute of Fisheries Education (CIFE), Mumbai \\ - 400061, INDIA \\ *Corresponding author. E-mail: manoj.fishco@gmail.com
}

Received: J uly 27, 2014; Revised received: 0 ctober 10, 2014; Accepted: November 23, 2014

\begin{abstract}
A study was undertaken to ascertain constraints faced by fish farmers in adoption of scientific aquaculture practices in East Champaran and West Champaran districts of Bihar. Information from 144 respondents was collected and analysed by calculating the Rank Based Quotient (RBQ) values. RBQ value for constraint faced by farmers were extreme climatic conditions (84.03), less extension programs and technical support (78.47), lack of contact with extension personnel's (71.33), lack of awareness about scientific culture practices (65.28), inadequate credit facility (60.42), labour scarcity (57.64) and higher cost of material input (52.08). These constraints could be categorised under five heads namely extension constraints, financial constraints, production constraints, marketing constraints and social constraints. Average RBQ value for constraints related to extension was found to be 71.76 and ranked first. This was followed by financial constraint with RBQ value of 52.78. Production related constraint ranked third with an average RBQ value of 49.3 followed by marketing (32.87) and social constraints(27.08). Hypothesis that there is no significant difference with reference to rankings of constraints was tested by single factor ANOVA. Null hypothesis was rejected as $\mathrm{F}_{\mathrm{tab}}=3.48>\mathrm{F}_{\mathrm{cal}}=2.61$ with $\mathrm{df}=4$ at $5 \%$ level of significance. There was a significant difference with reference to rankings of constraints. As the extension related constraints had the highest average RBQ value, it is clear that there is an urgent need of making effective strategy, engaging more fisheries extension professionals in this field along with capacity development of the existing extension professionals.
\end{abstract}

Keywords: Adoption, Constraints, Scientific aquaculture practices

\section{INTRODUCTION}

Economy of Bihar state is mainly dependent on agriculture, animal husbandry and fisheries. About $70 \%$ people are living in villages and their major source of income is from agriculture and allied sectors reported by Bihar Census (2011). Fisheries and aquaculture sector play a key role in food and nutritional security and rural livelihoods as significant proportion of population grow agriculture and horticulture crop, fisheries etc. for their livelihood sustenance and income. State of Bihar occupies fourth position in inland fish production (2.99 lakh tonnes) after West Bengal (12.46 lakh tonnes), Andhra Pradesh (10.79 lakh tonnes) and Uttar Pradesh (4.17lakh tonnes) in 2010-11 (Indiastat, 2014). Average fish production of the state was $800 \mathrm{~kg} / \mathrm{ha} /$ year which was well below the average fish productivity $(2500 \mathrm{~kg} / \mathrm{ha} / \mathrm{yr}$.) of India (DOF, 2008). It has been reported in Handbook of Fisheries Statistics (DOF, 2013) that fish production of state is 3.44 lakh tonnes whereas the demand is 5.20 lakh tonnes. Evidently, there exists a wide gap between demand (5.20 lakh tonnes) and production (3.44 lakh tonnes), which is quite paradoxical in view of the vast fisheries resources in the state. The unmet demand is partly met from supply of fish from other states. The annual demand of fish seed in the state is over 900 million, while the production is only about 350 million from the 121 government fish seed farms, two corporate level fish hatcheries, and 26 private hatcheries (DOF, 2012). Underutilization of aquaculture resources, unscientific management of water bodies and lack of entrepreneurship are some of the most obvious reasons for the gap between demand and supply (DOF, 2012). It is usually perceived that the reasons for underdeveloped fisheries and aquaculture in the state is due to poor institutional setup, weak extension services, lack of adequate resources and infrastructure facilities, defunct fisheries cooperative, lack of professionalism among fisheries personnel, fragmented social setup, poverty and illiteracy among the primary producers. Even when it is reported that the production from the ponds has gone up from about $600 \mathrm{~kg} / \mathrm{ha} /$ year in 1974 to 2.5 tonnes/ha/year (Ayyappan, 2011), still there are a number of constraints faced by the farmers in adopting aquaculture. Thus, a study was undertaken with the objective of studying the constraints faced by farmers in adoption of scientific aquaculture practices.

\section{MATERIALSAND METHODS}

This study was conductedin the selected 4 blocks (Motihari, Chhauradano, Pakadi Dayal and Patahi) from East Champaran and 4 blocks (Bettiah, Nautan, 
Chanpatia and Bairiya) from West Champaran districts of Bihar. These districts were purposively selected as it has vast and diverse inland fishery resources ideally suited for taking up scientific fish culture. A combination of purposive and simple random sampling procedures was employed for selection. Total eight blocks were selected for the study. These blocks served as the representative unit for the present study. A list of fish farmers was procured from the selected blocks. Eighteen fish farmers from each block were selected by using proportionate stratified random sampling technique. Data were collected with the help of structured and pre tested interview schedule. Based on the area under fish farming, six villages having more areas under fish farming in each selected blocks were purposefully selected for study. Thus, a total of 48 villages were selected. From each village, three farmers were randomly selected. Thus, a total of 144 respondents were selected for the study. Thereafter data were tabulated, analyzed and inferences were drawn in light of the objective.

Item writing for the constraints as regard to the adoption of aquaculture was done by farmers, experts, officials of Department of Fisheries. These constraints were later categorised under five heads namely extension constraints, financial constraints, production constraints, marketing and social constraints. Respondents were asked to rank these constraints. Rank Based Quotient (RBQ) was used to quantify the data collected by preferential ranking technique by first ranking the parameters and then calculating the RBQ given by Sabarathanam (1988), which is as follows:

$$
\text { R. B. Q }=\frac{\sum f i(n+1-i)}{N \times n} \times 100
$$

Where in, $\mathrm{fi}=$ number of farmers reporting to a particular problem under $i^{\text {th }}$ rank; $\mathrm{N}=$ number of farmers; $n=$ number of problems identified

As regards to constraints faced, possible inventory of suggestions has also been provided based on results of study, discussions with experts, officials of Department of Fisheries and farmers. The hypothesis that there is no significant difference with reference to the rankings of the constraints was tested by single factor ANOVA using MS excel.

\section{RESULTS AND DISCUSSION}

The constraints as reported by the fish farmers with their decreasing RBQ values as regards to adoption of scientific aquaculture practices are presented in Table 1.

It was observed from table 1 that the constraint extreme climatic condition was ranked first with a RBQ value of 84.03. The constraint less extension programs and technical support ranked second with a value of 78.47. Lack of contact with extension personnel was also reported to be a constraint which ranked third with a RBQ value of 71.53 and lack of awareness about scientific culture practices ranked fourth with RBQ value of 65.28.

Majority of respondents reported that even though subsidy was provided for construction and renovation of fish farms but inadequate credit facilities was a constraint and it scored fifth rank. Labour scarcity and high cost of labour was also reported to be a constraint. Further enquiry into this, revealed that this was possibly due to migration of labour outside the state and work provided by Mahatma Gandhi Rural Employment Guarantee Act (MGNREGA) scheme. Even if labour was available, extreme shortage of skilled labour was reported. It was difficult for the farmers' specially marginal and small farmers to afford labour cost as this was in the range of Rs. 200-300/day. It was observed that farm owners and their family members were involved in undertaking farm related activities. However, medium and big farmers employed unskilled labours at the farm.

Other constraints reported by the farmers were, high cost of material inputs, high transportation charge and difficulty in accessing farm inputs. Most of the farmers were marginal/small farmers and they could not afford farm machineries due to their high cost. Farmers reported that they were also paying high cost of diesel because of less availability of electricity to run water pumps.

Low level of co-operation among farmers was the eighth major constraint reported by farmers. They reported that usually they do not share the new information and other useful knowledge among them selves. Less availability of quality seed was also reported to be a constraint along with price fluctuation and marketing of the produce. The price of fish at the time of study was found to be Rs. $175-250 / \mathrm{Kg}$.

Low level of education of fish farmers $(22.92 \%)$ was reported to be a constraint. Most of the fish farmers belonged to Mallah (traditional fishers) community. Among the traditional fishing community the educational level has been reported to be relatively low (Bansil, 2011).In the present study too, education level of respondents who belonged to the mallah community was low. A total of $6.3 \%$ were illiterate, $50.8 \%$ had primary level of education followed by $14.3 \%$ having middle level education. A total of $11.1 \%$ had high school level education and7.9\% had higher secondary and $9.5 \%$ were graduate. Issues related to poaching were reported to be a constraint but it ranked last and the RBQ value too was less i.e., 9.72.

Similar studies in the field of fisheries are few. But, in a study on differences in district extension leaders' perceptions of the problems and needs of Tennessee small farmers, it has been reported by Ekanem et al., (2001) that capital, credit, and appropriate technology were some of the problems that small farmers faced. In a study on adoption behaviour of wheat growing farmers, it has been reported by Kumbhare and Singh (2011) that the major constraints faced by farmers 
Table 1. Ranking of constraints by fish famers in adopting scientific aquaculture practices.

\begin{tabular}{llcc}
\hline S. No. & Constraints & RBQ value & Rank \\
\hline 1 & Extreme climatic conditions & 84.03 & I \\
2 & Less extension programs and technical support & 78.47 & II \\
3 & Lack of contact with extension person & 71.53 & III \\
4 & Lack of awareness about scientific culture practice & 65.28 & IV \\
5 & Inadequate credit facility & 60.42 & V \\
6 & Labour scarcity & 57.64 & VI \\
7 & High cost of material input & 52.08 & VII \\
8 & Low level of cooperation among farmers & 48.61 & VIII \\
9 & High labour charge & 45.14 & IX \\
10 & Less availability of quality seed & 40.97 & X \\
11 & High transportation charge & 36.11 & XI \\
12 & Price fluctuation & 32.64 & XII \\
13 & Marketing & 29.86 & XIII \\
14 & Low level of education & 22.92 & XIV \\
15 & Difficulty in meeting farm inputs & 14.58 & XV \\
16 & Poaching & 9.72 & XVI \\
\hline
\end{tabular}

were technical and marketing constraints.

In the present study, constraints as reported by the fish farmers as regards to adoption of scientific aquaculture practices could be categorised under five heads namely extension constraints, financial constraints, production constraints, marketing constraints and social constraints. This is presented in Table 2 along with the RBQ values and possible suggestions. This is followed by average RBQ values for each category.

Out of these, average RBQ value for the constraints related to extension was found to be 71.76 and this ranked first. This was followed by financial constraint with RBQ value of 52.78. Production related constraint ranked third with an average RBQ value of 49.3 followed by marketing (32.87) and social constraints with a value of 27.08 .

The hypothesis that there is no significant difference with reference to the rankings of the constraints was tested by single factor ANOVA using MS excel. The null hypothesis was rejected as $\mathrm{F}_{\mathrm{tab}}=3.48>\mathrm{F}_{\mathrm{cal}}=2.61$ with $\mathrm{df}=4$ at $5 \%$ level of significance. It could thus be concluded that there is a significant difference with reference to the rankings of constraints.

As regards to the constraints faced the possible inventory of suggestions were also provided based on the results of study, discussions with experts, officials of Department of Fisheries, farmers as well as review of literature.

It is suggested that stocking the yearlings will help to avoid consequence of extreme weather conditions. For growing yearling only few ponds may be required. Special arrangements for only such few ponds may be made to overcome the extreme weather conditions. Large farmers, hatchery owners and seed growers may be encouraged to produce yearlings.

The study highlights that there is an urgent need of engaging more fisheries extension professionals in this field along with capacity development of the existing extension professionals. Emphasis on capacity building of farmers through training and extension will help in horizontal as well as vertical expansion of the sector. Use of opinion leaders in the form of farmers friends, field Schools and producers company may be introduced to strengthen extension programme. Extension of scientific aquaculture practices should reach village level. Extension agents should frequently visit the farmer's field. A visit schedule of the officers needs to be made so that farmers are able to contact the department staffs at least once in a month. Awareness about scientific practices can be improved by strengthening extension programmes. The success stories of farmers need to be popularised among fellow farmers that will enhance the interest and confidence of farmers in such technology. This will result in better adoption scientific aquaculture practices.

Average RBQ value for the constraints related to finance was found to be 52.78 and scored second rank. It is true that adoption of scientific aquaculture practices not only enhances the production but also generate income and employment opportunity for rural people but this requires significant investments. Majority of farmers are poor and aquaculture require huge investment in initial stage which some time work as hindrance in expansion of aquaculture. Lack of easy finance also hampers the adoption of scientific aquaculture practices by fish farmer. Therefore, there is a need to further strengthen the institutional finance easily available to farmers at the time of need. 
Table 2. Constraints perceived by famers in adopting scientific aquaculture practices.

\begin{tabular}{|c|c|c|c|}
\hline S. No. & Constraints & $\begin{array}{l}\text { RBQ } \\
\text { value }\end{array}$ & Possible suggestions \\
\hline A. & Extension constraint & & \\
\hline 1. & $\begin{array}{l}\text { Less extension programs and } \\
\text { technical support }\end{array}$ & 78.47 & $\begin{array}{l}\text { Capacity building of farmers. Farmers Friends and } \\
\text { Farmers Field School through Trickle Down System of } \\
\text { Aquaculture Extension to be introduced. }\end{array}$ \\
\hline 2. & $\begin{array}{l}\text { Lack of contact with extension } \\
\text { person }\end{array}$ & 71.53 & Increase in visit plans of extension professional \\
\hline 3. & $\begin{array}{l}\text { Lack of awareness about scien- } \\
\text { tific culture practice }\end{array}$ & 65.28 & $\begin{array}{l}\text { Strengthen extension programmes. Awareness through } \\
\text { posters, leaflets, radio talks and TV talks needs to be } \\
\text { explored. }\end{array}$ \\
\hline B. & Financial constraint & & \\
\hline 1. & Inadequate credit facility & 60.42 & $\begin{array}{l}\text { Strengthen institutional finance availability } \\
\text { Business Correspondents/retail agents selected for } \\
\text { financial inclusion by banks for providing banking } \\
\text { services at locations other than a bank branch/ATM } \\
\text { may be identified among fish farmers/fishers to facilitate } \\
\text { credit services }\end{array}$ \\
\hline 2. & High labour charge & 45.14 & $\begin{array}{l}\text { Small farmers may be allowed to utilize services of } \\
\text { MGNREGA. }\end{array}$ \\
\hline C. & Production constraint & & \\
\hline 1. & Extreme climatic conditions & 84.03 & $\begin{array}{l}\text { Stocking of yearling to avoid consequence of extreme } \\
\text { weather conditions }\end{array}$ \\
\hline 2. & Labour scarcity & 57.64 & Encourage farm mechanization \\
\hline 3. & Availability of quality seed & 40.97 & $\begin{array}{l}\text { Promote mini hatcheries. } \\
\text { Strict seed certification by Government is needed }\end{array}$ \\
\hline $\begin{array}{l}4 . \\
D .\end{array}$ & $\begin{array}{l}\text { Difficulty in mobilizing farm } \\
\text { inputs } \\
\text { M arketing constraint }\end{array}$ & 14.58 & $\begin{array}{l}\text { Clusters of farmers may develop one-stop-aqua-shop to } \\
\text { meet input requirement of cluster-members }\end{array}$ \\
\hline 1. & High transportation charge & 36.11 & $\begin{array}{l}\text { Cluster farming to reduce transportation costs of inputs/ } \\
\text { outputs }\end{array}$ \\
\hline 2. & Price fluctuation & 32.64 & $\begin{array}{l}\text { Facilities for storage, processing and product development } \\
\text { through public and private intervention }\end{array}$ \\
\hline 3. & Marketing infrastructure & 29.86 & $\begin{array}{l}\text { Developing infrastructure of existing market, farmers } \\
\text { cooperatives }\end{array}$ \\
\hline E. & Social constraint & & \\
\hline 1. & $\begin{array}{l}\text { Low level of education to } \\
\text { understand technology and } \\
\text { government scheme }\end{array}$ & 22.92 & Compatible extension literature for semi-literate adopters \\
\hline 2. & $\begin{array}{l}\text { Low level of cooperation } \\
\text { among farmers }\end{array}$ & 48.61 & Cluster farming \\
\hline 3. & Poaching & 9.72 & Cluster farming \\
\hline
\end{tabular}

Labour scarcity in the area was also perceived as a problem. Encouraging farm mechanization may be an option to overcome this problem. High cost of material input was also perceived as constraint. Low cost aquaculture may also be tried to lower down the input cost. Co-operation between farmers may be enhanced by forming clusters at the block level. Most cooperating cluster may be awarded at the district level.To overcome the high labour charges, small farmers may be allowed to utilize the services of MGNREGA scheme. Availability of quality seed may be enhanced by promoting mini hatcheries in the area.
Government should give importance towards the construction of scientifically managed new hatcheries which will distribute good quality and required quantity seeds to the farmers. Strict seed certification should be implemented by Government, so that good quality seeds should be available to the farmers. Therefore, capacity building of hatchery owners and seed grower for quality seed production will go a long way in enhancing the quality of fish seed and ultimately fish production in the state.

Suggestion of cluster farming is being proposed through this study as this may reduce the transportation 
costs of inputs and outputs. Clusters of farmers may develop one-stop-aqua-shop to meet the input requirement of the cluster-members and this will be helpful to avoid poaching too. Cluster farming as reported by Montiflor (2008); Montiflor et al., (2009) and Velmurugan and Naik (2013) is an alternative farming strategy for smallholder farmers. The main objectives of cluster farming are to consolidate smallholder farmers' produce, to deliver in bulk to save on transport and transaction costs, and to increase income. Majority of the farmers believe that they were financially better off after joining the cluster. Participating farmers received other mostly non-monetary benefits such as improved access to wet and institutional markets, market information, market and production linkages, technical and financial support, and production inputs.

Price fluctuation may be controlled by creating facilities for storage, processing and product development through public and private intervention. Earning profit from fish is the ultimate aim of the farmers. However, marketing of fish is confronted with problems of inadequate marketing facilities. This problem can be solved by developing infrastructure of the existing market in the state and also by encouraging farmers for forming marketing co-operatives which will increase their capacity to negotiate with buyers.As the producers have very low level of formal education, the extension literatures may be more compatible for semi-literate adopters.

\section{Conclusion}

The present study has revealed that fish farmers face a number of cconstraints in adoption of scientific aquaculture practices. These constraints could be categorised under five heads namely extension constraints, financial constraints, production constraints, marketing constraints and social constraints. Average RBQ value for the constraints related to extension was found to be highest. The study highlights that there is an urgent need of effective strategy and engaging more fisheries extension professionals in this field along with capacity development of the existing extension professionals.

\section{ACKNOWLEDGEMENTS}

Authors sincerely acknowledge Dr. W.S. Lakra,
Director, CIFE, Mumbai and Dr. M. Krishanan, Head, FEES division, CIFE, Mumbai for proving the necessary facilities for conducting the present study.

\section{REFERENCES}

Ayyappan, S., Moza, U., Gopalakrishan, A., Meenakumari, B., Jena, J.K. and Pandey, A.K. (2011). Handbook of fisheries and aquaculture, Directorate of Knowledge Management in Agriculture, ICAR, New Delhi, India pp 380.

Bansil, P.C. (2011). Bihar agriculture: A perspective. Concept publishing company Pvt. Ltd. ISBN-13: 978 -81-8069-743-2.

Bihar Census (2011). Published by Government of India

DOF, (2008). Draft Fisheries Policy. Published by Directorate of Fisheries. Government of Bihar Department of Animal and Fish Resources, Bihar pp. 7.

DOF, (2012). Draft Fisheries Policy. Published by Directorate of Fisheries. Government of Bihar Department of Animal and Fish Resources, Bihar pp. 4.

DOF (2013). Handbook of fisheries statistics. Published by Directorate of Fisheries. Government of Bihar Department of Animal and Fish Resources, Bihar pp. 3.

Ekanem, E., Singh, S.P., Safdar, Muhammad, Fisseha Tegegne and Anonya, Akuley-Amenyenu (2001). Differences in District Extension Leaders' Perceptions of the Problems and Needs of Tennessee Small Farmers. J ournal of Extension, 39: Number 4, (August)

Indiastat (2014). State-wise inland fish production in India (2000-2002 to 2012-2013), Retrieved September, 23, 2014 fromhttp://www.indiastat.com/table/agriculture/2/ fish production19502013/450250/38469/data. aspx.

Kumbhare, N.V. and Singh, K.(2011). Adoption behaviour and constraints in wheat and paddy production technologies. Indian Res. J. Ext. Edu. 11 (3): 41-44.

Montiflor, M.O. (2008). Cluster farming as a vegetable marketing strategy: the case of smallholder farmers in southern and northern Mindanao. Acta Horticulture, International Society for Horticultural Science (ISHS) 794:229-238.

Montiflor, M.O., Batt, P.J. and Murray-Prior, R. (2009). Socio-economic impact of cluster farming for smallholder farmers in southern Philippines. Acta Horticulture, International Society for Horticultural Science (ISHS) 809:193-200

Sabarathanam, V.E., (1988). Manual of field experience training for ARS Scientists. Published by NAARM, ICAR, Hyderabad.

Velmurugan, R., Naik V.R. (2013). Cotton-cluster bean intercropping system for better farming. BIOINFOLET A Q uarterly J ournal of Life Sciences. 10: 33-34. 